\title{
Study on Agricultural Management for Sustainable Agriculture in Zhangye Oasis, Middle Reaches of Heihe River Basin
}

A case study in Linze County

\author{
Manru Zhou $^{1 *}$, Atsushi Ozaki ${ }^{2}$, Kazuki Kobayashi ${ }^{2}$, Takuma Kozono ${ }^{2}$, Makoto \\ Kanasugi $^{2}$ \\ 1 Graduate School of Global Environmental Studies, Sophia University \\ 2 Graduate School of Bio-Applications and Systems Engineering, Tokyo University of \\ Agriculture and Technology \\ *Corresponding Author, Email: zhoumr1990@hotmail.com
}

Received: Dec 15, 2016; Accepted: Jan 15, 2017

Key words: Sustainable agriculture, Agricultural management, Irrigation, Fertilizer, Zhangye Oasis

\begin{abstract}
Proper management of irrigation and fertilizer for different crops is beneficial to the sustainable development of agriculture. Zhangye Oasis, which is an arid region surrounded by water dependent agricultural areas with canal-type irrigation systems, has been utilising the majority portion of the discharge of Heihe River. Maize is the dominant cash crop, while the cultivation of a new cash crop, stevia, has also been under expansion in recent years. This study was conducted with both a social survey approach and science experiment approach, aiming to comprehensively understand the management of irrigation, fertilizer and soil data, simultaneously. The water consumption, fertilizer application and soil condition of stevia and maize fields in Linze County were investigated and compared. The social survey on the perception of farmers revealed that the cultivation of stevia, which had greater cash ability, required less fertilizer than maize cultivation, while water consumption showed little difference. The nitrate and ammonium contents of stevia fields were higher than those of maize fields, indicating that stevia fields could be cultivated with less chemical fertilizer. The result that the nitrate contents in the middle and lower soil samples were higher than those in upper soil samples, suggests nitrate leaching. According to the results, it is suggested that less chemical fertilizer can be applied and less water used for irrigation in stevia fields of the Zhangye Oasis, and there is therefore a good opportunity for adopting stevia as a new type of cash crop for sustainable agriculture, with improved management of irrigation and fertilizer usage.
\end{abstract}

\section{INTRODUCTION}

\subsection{The contradiction of water scarcity and water consumptive agriculture in Zhangye Oasis}

Zhangye Oasis is located in the middle reaches of Heihe River Basin, Gansu Province in the Northwest of China. As reported by The State Council 
Information Office of the People's Republic of China (2015), 95\% of the arable land, $91 \%$ of the population, $83 \%$ of the water consumption and $89 \%$ of GDP of the region is concentrated in Heihe River Basin. It is surrounded by arid and irrigated agricultural areas and has developed into an important base for maize and vegetable cultivation in China. The large expansion of agriculture in this region requires a great amount of water for irrigation. Annual precipitation is under $200 \mathrm{~mm}$, while annual evaporation is above $2000 \mathrm{~mm}$ (Yang, R. \& Liu, 2010; Huang, 2015). The $1800 \mathrm{~mm}$ difference between evaporation and precipitation means that this region suffers from water scarcity. This also explains why the impact of water use for agriculture is high in this region.

Although natural water scarcity is obviously one of the biggest problems in this region, excessive irrigation in agricultural practice occurs ordinarily, resulting in significant inefficient use of water. It has been reported that more than $75 \%$ of the water resources from the discharge of Heihe River is used for irrigating the cultivated land (Nian et al., 2014). Since the irrigation system, which is a unique canal irrigation system, is easily accessed and there is no mechanism to improve farmers' awareness of saving water, the phenomenon of a "communal watering system" has become very common

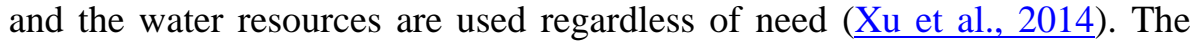
current use of the irrigation system appears to be irrational because the irrigation efficiency is low and only $52 \%$ of the total irrigated amount was used to fulfil the plant evapotranspiration requirement in 2012 (Wu et al., 2015). Because of the development of agriculture, especially in maize cultivation, coupled with the situation of water scarcity, this region has been consuming a huge amount of the Heihe River water resource for irrigation and has even resulted in drought issues in the downstream areas, such as the drying up of the terminal lake (Xiao et al., 2004). Under the contradiction of water scarcity and water consumptive agriculture, there is an urgency to develop sustainable agriculture that can preserve the Heihe River water resource in the Zhangye Oasis.

\subsection{Overuse of chemical fertilizer in agriculture}

Excessive irrigation rates and use of chemical fertilizer are considered conventional agricultural practice in the middle reaches of the Heihe River Basin (Yang, R. \& Wang, 2011). Overuse of chemical fertilizer, especially nitrogen fertilizer, is considered another serious issue in the area. Nitrogen fertilizers have been assisting agricultural cultivation for more than 100 years, since two German scientists developed a way to transfer nonreactive atmospheric nitrogen to reactive ammonium, which forms the base of nitrogen fertilizer $(\underline{S m i l, 2004})$. Overuse of nitrogen fertilizer in agricultural activities could cause serious environmental issues and human hazards. Large quantities of nitrate leaching from soil to groundwater caused by the application of chemical fertilizer can result in high levels of nitrate concentrated in groundwater (Addiscott, Whitmore, \& Powlson, 1991) and high levels of nitrate accumulating in foods and drinking water, which is the source of dietary nitrate that can cause human health disorders, as had been found decades ago (Wilson, 1949; Meah, Harrison, \& Davies, 1994). The concentration of nitrate in foods is primarily attributed to overuse of nitrogen fertilizer (Addiscott, Whitmore, \& Powlson, 1991; Good \& Beatty, 2011).

In China, the use of fertilizers has been increasing dramatically since the 1970s (Jiang \& Li, 2016). It has been reported that nitrogen fertilizer was applied in enormous amounts, from 500 to $1900 \mathrm{~kg}$ nitrogen $\mathrm{ha}^{-1}$ year $^{-1}$ in 
locations with a high nitrate concentration in the ground water (Zhang, W. et al., 1996). Nitrate concentration has been observed increasing in Zhangye agricultural areas as well. In 2005, the total amount of nitrogen fertilizers applied on maize fields was more than $300 \mathrm{~kg} \mathrm{ha}^{-1} \mathrm{year}^{-1}$, and was more than $450 \mathrm{~kg} \mathrm{ha}^{-1}$ year $^{-1}$ more recently ( $\mathrm{Su}$, Zhang, \& Yang, 2007). Effects of long-term fertilization on soil productivity and nitrate accumulation in the Zhangye region have been researched by Yang, S.-M. et al. (2006). They found that the accumulation and distribution of nitrate in soil were significantly affected by annual fertilizer application and fertilizer led to nitrate accumulation in most subsoil layers. They also suggested that it was of great importance to manage the application of chemical fertilizer and organic fertilizer in order to protect the soil and underground water from potential nitrate contamination while sustaining high productivity in the oasis agro-ecosystem. With the development of agriculture, Zhangye Oasis has recently grown into the largest maize production area in China. However, it is quite clear that the overuse of chemical fertilizer in the cultivation of maize is not sustainable.

\subsection{Current agricultural management in general}

In the Zhangye Oasis, large scale agriculture activities are carried out during the farming period from March to November (Yin \& Wang, 2015). During this period, water resources from the discharge of Heihe River are delivered by a unique canal type irrigation system to each individual area of farmland in the Zhangye Oasis. More than $75.6 \%$ of all the villages have canals passing through (Jiao \& Ma, 2002). There are five levels of canals: the main, branch, lateral and field canals, and field ditch. Annually, irrigation activities are conducted about six times (every 20 days from early June to September). For preventing leakage from irrigation canals and to improve water efficiency given the limited water resources, a high proportion of the canals has been paved with concrete. As of 2013, the main and branch canals had extended to $4,700 \mathrm{~km}$ and had been paved, the total length of the lateral and field canals had reached $14,000 \mathrm{~km}$, and the lateral canals had almost been completely paved, while only $30 \%$ of the field canals had been paved (Wang et al., 2013). According to Xu et al. (2014), since accesses to water resources for local residents is easy to take advantage of in the Zhangye Oasis, by all water users and to any extent, and with no mechanism to improve water users' awareness of saving water, the phenomenon of water wastage has become serious.

Chemical fertilizer application, as well as irrigation, is also conducted during the farming period. Conventionally, some of the farmers apply organic manure to fertilize the soil at the first stage of farming before cultivating crops. Then, two or three times, chemical fertilizer is applied following cultivation. Nitrogen fertilizers, such as urea and ammonium phosphate, other phosphorus fertilizers, and potassium fertilizers are used. Cases of using mixed fertilizer are also not rare. In rural areas of this region, farmers are relatively lowly educated and tend to apply chemical fertilizer based on either their own experiences or on recommendations from other farmers. In this kind of situation, farmers tend to overuse chemical fertilizer to make sure that their fields obtain enough nutrients. As a matter of fact, in each village of Zhangye, there are Agricultural Technology Stations which are expected to take responsibility for teaching farmers how to manage irrigation and fertilizer, and spreading other farming knowledge. Surprisingly, these stations have deferred to being retailers of fertilizers for 
profit, which is obviously contradictory to the responsibilities of the farmers who run them, and will become an obstacle to the sustainable development of agriculture in the Zhangye Oasis.

Excessive irrigation and chemical fertilizer application may result in low efficiency of applied resources and lead to soil and groundwater contamination (Al-Kaisi \& Yin, 2003). With the urgency to conserve water resources and prevent soil contamination, the economic investment in all kinds of water conservation projects in Gansu province had reached almost 7

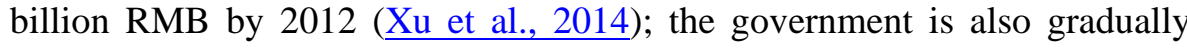
making efforts to reduce excessive chemical fertilizer application.

\subsection{Stevia as a new cash crop for irrigated agriculture in Zhangye Oasis}

In Zhangye Oasis, maize cultivation, which accounts for over $25 \%$ of the total planting area in the basin, expanded to be the dominant cash crop from the 2000s (Huang, 2015), while the cultivation of vegetables, which require green houses and a large amount of water and fertilizer for cultivation because of the frigid winter climate in winter, and some medicinal herbs, have also showed high cash ability in recent years.

Stevia is a perennial, calorie free naturally sweet herb that belongs to the family Asteraceae (Ahmed et al., 2007; Ojha, Sharma, \& Sharma, 2010). It is native to South and Central America (Debnath, 2008; Jackson et al., 2009). The first commercial cultivation of stevia started in Paraguay around 1964 (Sumida, 1968; Katayama et al., 1976). Currently it is found cultivated in Japan, Taiwan, Philippines, Hawaii, Malaysia and overall South America for food and pharmaceutical products (Kassahun et al., 2012). The economic value of stevia is much higher than maize. According to The Statistics Portal (2017), the global market for stevia was estimated to have a value of 336 million U.S. dollars in 2014, and the latest estimated value increased to 578 million U.S. dollars in 2017.

In Zhangye Oasis, it was found that the soil in Linze County is suitable for cultivating stevia and the cultivation of stevia (Stevia rebaudiana L. Bertoni) started in 2007, in only several scattered fields at first (Zhou et al., 2009). The price of stevia leaves has kept increasing in recent years. It was reported to be $7 \mathrm{RMB} \mathrm{kg}^{-1}$ by Zhou et al. (2009), and the profit was 1502800 RMB per $1 \mathrm{mu}$ (1/15 hectare, Chinese unit of area) field. Then, in 2015 and 2016, as reported by the Zhangye Agriculture Bureau (2015) and Zhangye Audio and Visual Network (2016), the price rose up to10 RMB kg ${ }^{1}$, and the profit also rose to $3650-4000 \mathrm{RMB} \mathrm{mu}^{-1}$. In good cases it was as high as $4600 \mathrm{RMB} \mathrm{mu}{ }^{-1}$. Through this study, it is proposed that cultivating more stevia and reducing maize cultivation in order to save water, reduce chemical fertilizer application and gain better economic benefits, might be a new solution for developing sustainable agriculture in the Zhangye Oasis.

\subsection{Significance}

Although irrigation and chemical fertilizer greatly increase agricultural production potential, in Zhangye Oasis the high water consumption, negative impact on the soil environment, related groundwater pollution and other issues could not be justified. The Ministry of Water Resources (MWR) of China initiated a pilot project in Zhangye City in 2002, the Building Water Saving Society (Huang, 2015). Considering that the agricultural 
management of irrigation and fertilizer may be conducted improperly by local farmers, the present study aims to capture a comprehensive understanding of the current condition of agricultural management and also intends to identify the feasibility for stevia as a new cash crop for more sustainable agriculture, by revealing the management information and soil data of cultivation fields. The results of this study, revealing evident proof of the current soil condition, responds to the government policy of the Building Water Saving Society and can contribute to reduced chemical fertilizer application for sustainable agriculture in the Zhangye Oasis.

\section{MATERIAL AND METHODS}

\subsection{Study area}

Zhangye Oasis, as shown in Figure 1, is located in the middle reaches of Heihe River Basin, which flows from Yingluoxia Valley to Zhengyixia Valley. In this region, around $70 \%$ of the land was reportedly used as agricultural land (Yang, R. \& Liu, 2010). In Linze County, as reported by Linze Government Network (2017), the population is 146,000 and work for $86 \%$ of the population is directly related to agriculture activities. Stevia is cultivated densely and the total area cultivated until 2016 was around 35,000 $\mathrm{mu}$, stated by the Zhangye Audio and Visual Network (2016). Yanuan Town in Linze County is one of the areas that first attempted stevia cultivation in 2007 and this attempt turned out to be a great success (Zhang, B., 2016), and significant expansion of stevia cultivation has since been witnessed. Until 2016 in Yanuan Town, the total area of stevia cultivated reached 24,000 mu, of which was $10,000 \mathrm{mu}$ in 2015 , according to the Zhangye Government Network (2016). Consequently, the study area is set to be Yanuan Town.

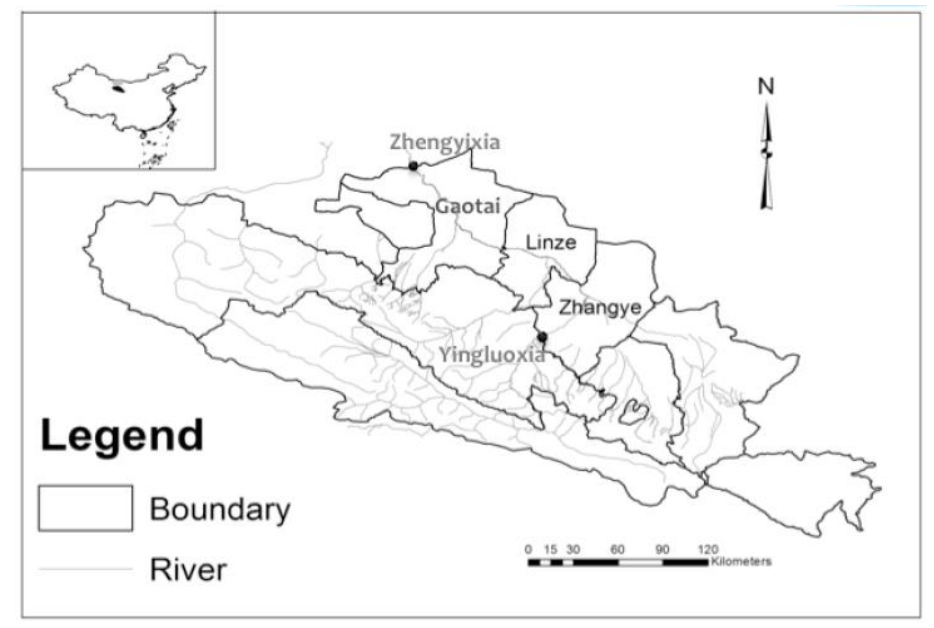

Figure 1. Middle reaches of Heihe River Basin

\section{$2.2 \quad$ Methods}

The present study was conducted using a social survey approach, as well as a scientific experimental approach. The study period is August $1^{\text {st }}$ to August $15^{\text {th }} 2015$, with fertilization having been finished prior to the study period. Interviews with stevia and maize farmers were designed to find out 
about the current agricultural management practices and famers' perceptions of fertilizer and water consumption. Experiments were conducted to investigate the soil data $(\mathrm{pH}$, nitrate concentration, nitrification potential, etc.) of stevia and maize fields in order to reveal the soil conditions, and also for comparison.

\subsubsection{Social survey approach}

A social survey for achieving a comprehensive understanding of the current management practice in the study area was performed. In the Linze County of Zhangye Oasis, 44 valid interviews of stevia farmers, who were cultivating maize at the time or who had experiences of cultivating maize, were interviewed, mainly in Zhaowu Village and Nuanquan Village of Yanuan Town, Linze County.

\subsubsection{Experimental approach}

Soil samples were collected from stevia and maize fields using a root auger (4 cm diameter; Daiki Rika Kogyo Co. Ltd., Kounosu, Japan) and divided into three categories: Upper $(0-10 \mathrm{~cm})$, Middle $(10-30 \mathrm{~cm})$ and Deeper $(30-60 \mathrm{~cm})$. Five points were randomly picked from each field for sampling. The attributes of soil experiments and sampling methods are listed in Table 1, below.

Table 1. Soil attributes and experimental methods

\begin{tabular}{|c|c|}
\hline Attributes & Experimental methods \\
\hline Soil Hardness & $\begin{array}{l}\text { Soil hardness is measured using a digital penetration type soil } \\
\text { hardness tester (DIK-5531; Daiki Rika Kogyo Co. Ltd., Japan). }\end{array}$ \\
\hline Percolation Rate & $\begin{array}{l}\text { Set a cylinder on the ground and pour the set amount of water } \\
\text { through fully. The volumes of the penetrated water into the ground } \\
\text { per minute are measured } 10 \text { times. Percolation rate is estimated } \\
\text { using the average of stable values from } 6 \text { to } 10 \text { times. }\end{array}$ \\
\hline $\mathrm{pH}$ & $\begin{array}{l}\text { Soil sample }(10 \mathrm{~g}) \text { is added to deionized water }(25 \mathrm{~mL}) \text {, and shaken } \\
\text { for } 60 \text { minutes. } \mathrm{pH} \text { is measured using a LAQUA twin water quality } \\
\text { analyzer (Horiba Ltd., Japan). }\end{array}$ \\
\hline $\mathrm{NO}_{3}{ }^{-}$Concentration & $\begin{array}{l}\text { Soil sample }(5 \mathrm{~g}) \text { is added to deionized water }(25 \mathrm{~mL}) \text {, shaken for } 30 \\
\text { minutes and filtered. } \mathrm{NO}_{3} \text { concentration was measured using an RQ } \\
\text { flex plus } 10 \text { reflectometer (Fujiwara Scientific Co. Ltd., Japan). }\end{array}$ \\
\hline $\mathrm{NH}_{4}{ }^{+}$Concentration & $\begin{array}{l}\text { Bremner Method: Soil sample }(2 \mathrm{~g}) \text { is added to } 2 \mathrm{M} \mathrm{KCl}(\mathrm{aq})(20 \\
\mathrm{mL}) \text {, shaken for } 60 \text { minutes and filtered. } \mathrm{NH}_{4}^{+} \text {concentration is } \\
\text { measured using RQ flex plus } 10 \text { reflectometer. }\end{array}$ \\
\hline Nitrification Potential & $\begin{array}{l}\mathrm{NO}_{3}{ }^{-} \text {concentration in soil sample }(5 \mathrm{~g}) \text { is detected first. Another part } \\
\text { of the soil sample }(5 \mathrm{~g}) \text { is added with }\left(\mathrm{NH}_{4}\right)_{2} \mathrm{SO}_{4}(9.4 \mathrm{~g}, 0.07 \mathrm{~mol}) \text {, } \\
\text { shaken, and incubated for two days at room temperature. Then the } \\
\text { same samples are added to deionized water }(25 \mathrm{~mL}) \text {, shaken for } 30 \\
\text { minutes and filtered. The difference between } \mathrm{NO}_{3}{ }^{-} \text {concentration } \\
\text { before and after incubation reflects the soil nitrification potential. }\end{array}$ \\
\hline $\mathrm{K}^{+}$Concentration & $\begin{array}{l}\text { Soil samples }(1 \mathrm{~g}) \text { are added with } 1.0 \mathrm{M} \mathrm{CH}_{3} \mathrm{COONH}_{4}(\mathrm{aq})(20 \mathrm{~mL}) \text {, } \\
\text { shaken for } 30 \text { minutes and filtered. } \mathrm{K}^{+} \text {concentration is measured } \\
\text { using RQ flex plus } 10 \text { reflectometer. }\end{array}$ \\
\hline
\end{tabular}




\section{RESULTS AND DISCUSSIONS}

\subsection{Current water and chemical fertilizer management}

The results of the current management of irrigation and fertilization from the social survey are listed in Table 2.

Table 2. Current water and chemical fertilizer consumption

\begin{tabular}{lll} 
Variable & Stevia & Maize \\
Water consumption $\left(\mathrm{m}^{3} / \mathrm{mu}\right)$ & $>1000$ & $>1000$ \\
Chemical fertilizer $(\mathrm{kg} / \mathrm{mu})$ & $<64$ & 64 \\
\hline
\end{tabular}

According to the results of the interview, usually, irrigation activities were conducted about six times a year (every 20 days from June to September). For both maize fields and stevia fields, average costs of irrigation water were a little more than $100 \mathrm{RMB}$ year $^{-1}$ for a $1 \mathrm{mu}$ field.

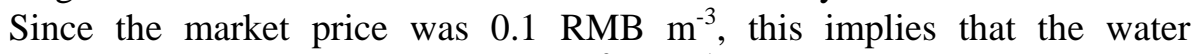
consumption was more than $1000 \mathrm{~m}^{3}$ year $^{-1}$ in a $1 \mathrm{mu}$ field. Stevia crop evapotranspiration for the total cycle (80 days) was estimated through a microlysimeter by Fronza and Folegatti (2003) and was found to be $464 \mathrm{~mm}$. Thus, in a $1 \mathrm{mu}$ field, the mean water demand for cultivating stevia is calculated to be $309.5 \mathrm{~m}^{3}$, meaning the current irrigation may be $690.5 \mathrm{~m}^{3}$ more than demand.

The application of chemical fertilizer (nitrogen, phosphorus and mixed fertilizer) in stevia cultivation is found to be smaller than that for maize cultivation, which is around $64 \mathrm{~kg} \mathrm{mu}^{-1}$ year $^{-1}$. The result is much larger than the amount of nitrogen fertilizer application that Su, Zhang et al. (2007) found, implying that there is a good possibility that chemical fertilizer in the study area has been overused, but almost all the farmers interviewed claimed that they would not reduce their chemical fertilizer use despite this because they might feel insecure with less chemical fertilizer application.

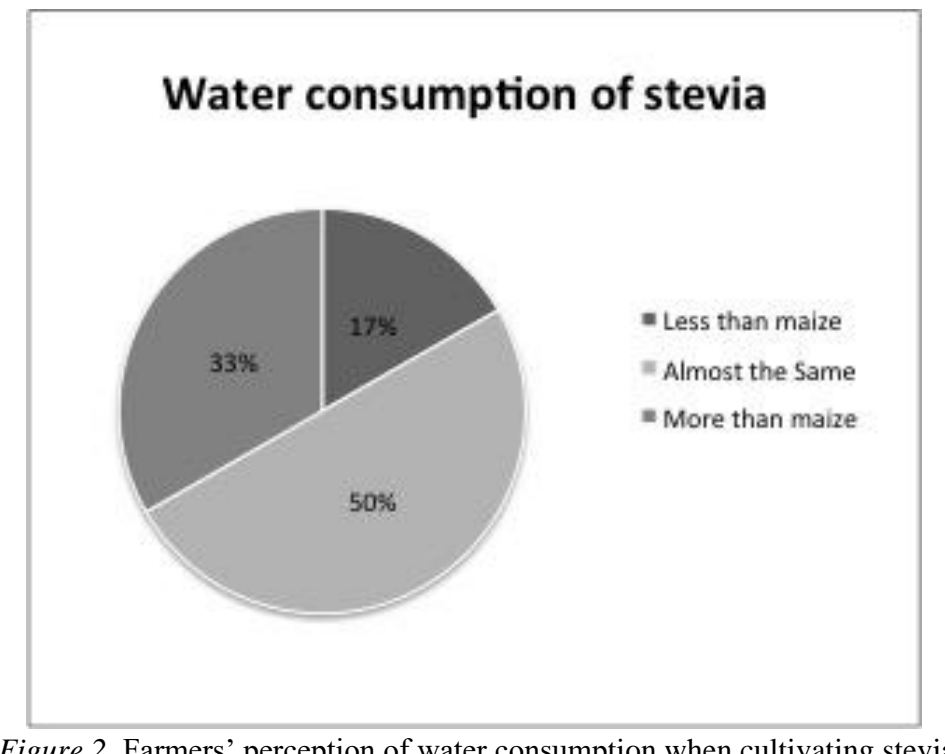

Figure 2 shows the farmers' perception of irrigating fields considering the different cultivation types. The results show half of them answered that they irrigated both stevia and maize fields with the same amount of water, indicating the difference between the water consumption of stevia and maize 
was not significant in current management. However, 1/3 of them answered that stevia fields might consume more water, while only $1 / 6$ of them answered stevia fields might save water.

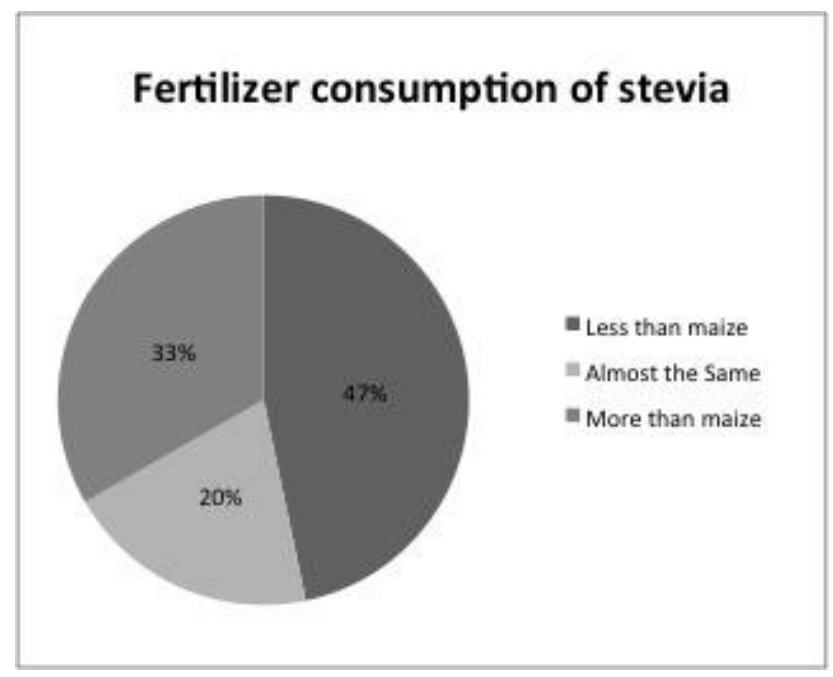

Figure 3. Farmers' perception of fertilizer consumption when cultivating stevia

Figure 3 above shows the farmers' perception of applying chemical fertilizer considering the different cultivation types. The results show that nearly half of all interviewees apply less chemical fertilizer to stevia fields than to maize fields, indicating that stevia cultivation might require less chemical fertilizer than maize.

According to the Ministry of Agriculture of the People's Republic of China (2015), the usage of pesticide is more than 2,000 tons every year in the Zhangye Oasis, with the average amount of $0.583 \mathrm{~kg} \mathrm{mu}^{-1}$, while a reasonable amount is only $0.307 \mathrm{~kg} \mathrm{mu}^{-1}$. As a result, about $0.276 \mathrm{~kg} \mathrm{mu}^{-1}$ of pesticide is over used and, incredibly, the total amount of 1,000 tons of pesticide is over used every year. On the basis of the social survey, the study team also found that compared to maize cultivation, which was always the subject of pest issues, the cultivation of stevia suffered less from pest issues, implying stevia cultivation could be eco-friendlier by reducing a large portion of the associated pesticide use. Unlike for maize contracted cultivation, in which the purchasing price is set to be 2000-2400 RMB mu under the contract of the purchasing company (from interviews), the stevia farmers could get paid as soon as the products were purchased and the price would increase along with the market price rising. Moreover, the stevia farmers also mentioned that the cultivation of stevia required a lower demand on physical labour compared to maize cultivation, which made their life easier and granted them more time to be involved in other industries, or to cultivate of other crops, as well as to have more time for their social life.

\subsection{Soil data}

The soil data of stevia and maize fields is investigated with experiments. Table 3 shows that the Percolation Rate, $\mathrm{pH}$ and Nitrification potential of soil from maize and stevia fields did not show much difference. The nitrification potential of soil from stevia fields $\left(\mathrm{NO}_{3}^{-} 32.3 \mathrm{mg} \mathrm{kg}^{-1}\right.$ dry soil day $\left.^{-1}\right)$ was slightly higher than that of maize cultivated soil $\left(\mathrm{NO}_{3}^{-} 31.1 \mathrm{mg}\right.$ $\mathrm{kg}^{-1}$ dry soil day ${ }^{-1}$ ).

Naturally, the root of normal crops grows in the soil layer between 0 and $15 \mathrm{~cm}$ (Karizumi, 2010). It has also been found that the root length of stevia 
grows to $14 \mathrm{~cm}$ (Singh \& Verma, 2015). The study conducted by Nakatsu (2004) showed that the roots of crops could not grow when soil hardness became higher than $2000 \mathrm{kPa}$. Figure 4 and Figure 5 below show that when the soil hardness was $2000 \mathrm{kPa}$, the soil depth of a stevia field was $23 \mathrm{~cm}$ and that of a maize field was $25 \mathrm{~cm}$, meaning both of the fields were suitable for crop roots to grow naturally.

\section{Table 3. Soil data results}

\begin{tabular}{lcc}
\hline Variable & Maize & Stevia \\
Percolation Rate $(\mathrm{mL} / \mathrm{min})$ & 8 & 9 \\
$\mathrm{pH}$ & 8.3 & 8.4 \\
Nitrification potential & 31.1 & 32.3 \\
$\left(\mathrm{NO}_{3}^{-} \mathrm{mg} / \mathrm{kg}\right.$ dry soil/day) & & \\
\hline
\end{tabular}

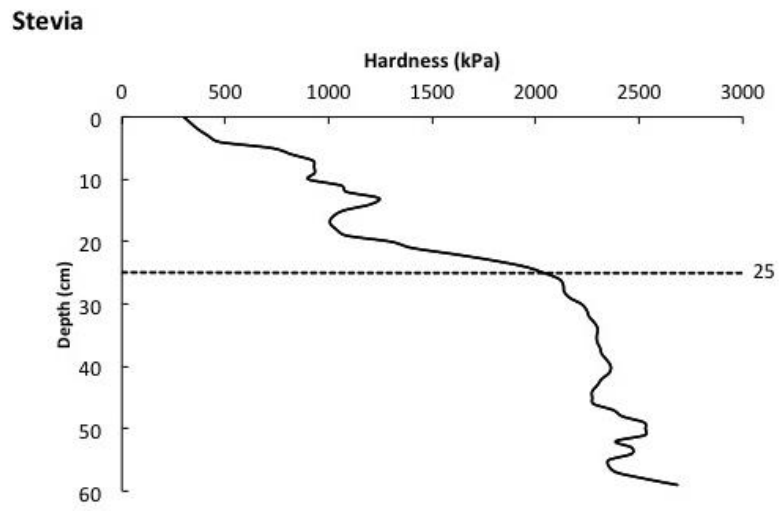

Figure 4. Soil hardness data of stevia field

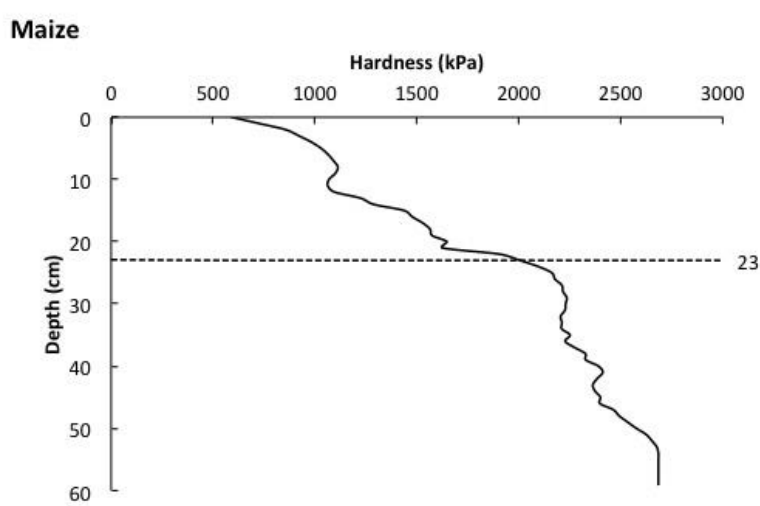

Figure 5. Soil hardness data of maize field

The nutrients (nitrate, ammonium, potassium) in the upper $(0-10 \mathrm{~cm})$, middle $(10-30 \mathrm{~cm})$ and lower $(30-60 \mathrm{~cm})$ layers of stevia and maize soils were also detected and the results were as shown in Figure 6, Figure 7 and Figure 8, below.

The accumulation of nitrate and ammonium in all layers of stevia soil was much higher than that in maize soil. This indicates that the nitrogen nutrients in stevia soil are richer than for those in maize soil. Combining these results with the perception of stevia farmers', that cultivating stevia consumed less chemical fertilizer, the study team conclude that much less chemical fertilizer application than the conventional amount could be enough for stevia soil. However, further study is needed for determining the optimal amount. 
In addition, nitrate leaching into subsoil layers was also found. Since the nitrate contents in the middle and lower layers are higher than for those in the upper layer of stevia soil, and the nitrate contents in the lower layer are higher than those in the upper and middle layers of maize soil, the result was identical to the results of a long-term study by Yang, S.-M. et al. (2006) and the study by $\mathrm{Su}$, Zhang, and Yang (2007).

Ammonium concentration in the upper and middle soil layers is found to be higher than that in the lower layer. This is because the ammonium, which is a component of the urea and ammonium fertilizer that is applied to the surface of soil in this region, easily binds to particles and is retained in the soil.

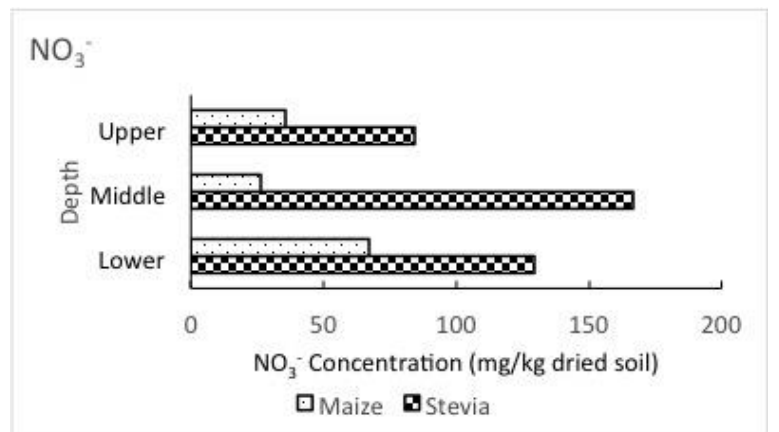

Figure 6. Nitrate concentration in soil layers of stevia and maize fields

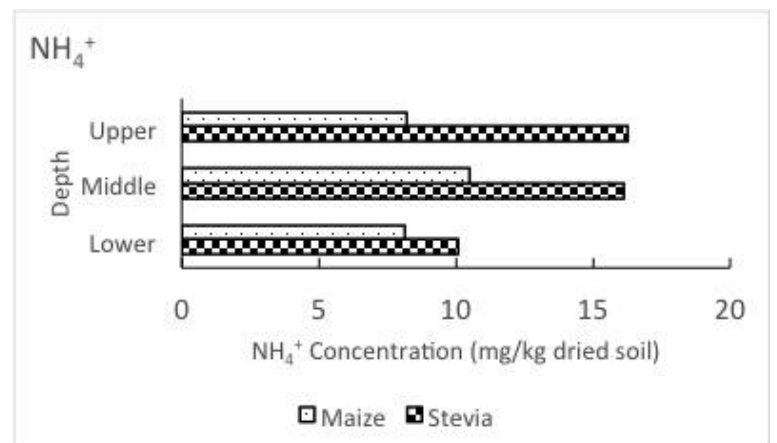

Figure 7. Ammonium concentration in soil layers of stevia and maize fields

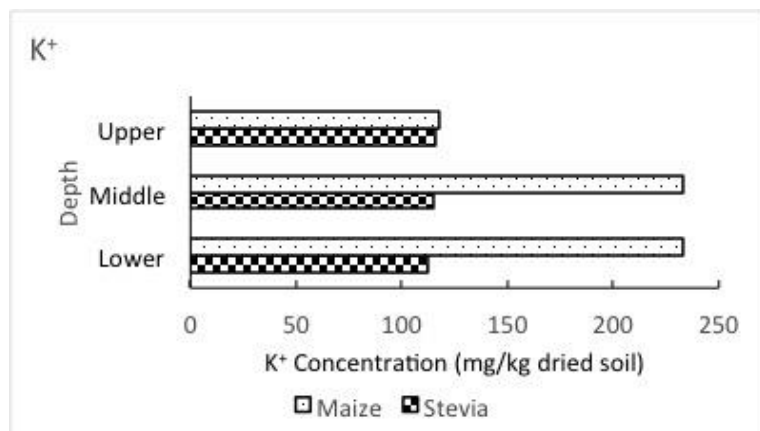

Figure 8. Potassium concentration in soil layers of stevia and maize fields

The potassium concentrations in the middle and lower layers of stevia soil are lower than for those in the maize soil. In considering only the potassium concentration in maize fields, the middle and lower layers concentrated much more potassium, possibly because of leaching induced by overuse of both fertilizer and irrigation water. 
Su, Zhang, and Yang (2007) also found there was no evident difference in water content in the $0-160 \mathrm{~cm}$ soil layer across three levels of irrigation treatment: conventional treatment, $10 \%$ water saving treatment and $20 \%$ water saving treatment, indicating that conventional irrigation treatment cannot conserve soil water for any longer of a period than water saving irrigation treatments. Considering over-irrigation induces nutrient leaching, it is reasonable to comment that reducing the volume of irrigation water to an optimal amount would contribute to sustainable agricultural management in the study area.

\section{CONCLUSIONS AND SUGGESTIONS}

The three pillars of sustainability are characterized as the environment, the economy and society. The present study, combining a social survey with scientific experiments, investigated the current agricultural management of irrigation and chemical fertilizer application and explored the possibility of adopting stevia as a new cash crop for the sustainable development of agriculture in the Zhangye Oasis.

Economically, stevia has showed high cash ability and is more profitable than the conventional cash crop, maize. Socially, a lower demand on physical labour during stevia cultivation can allow farmers to have sufficient time for other agricultural or industrial activities, or for their social lives. Most importantly, regarding envirmental sustainability, stevia cultivation is found to have a relatively lower necessity for chemical fertilizer and water for irrigation, which can result in conservation of the water resources of the Heihe River Basin and reduced soil contamination by reduced application of chemical fertilizer in the Zhangye Oasis. Stevia has the potential to be a new cash crop, and developing more areas of stevia cultivation can contribute to more sustainable agriculture. However, it is found that chemical fertilizer is overused in stevia fields and irrigation is also possibly exceeding the optimal amount in its current agricultural management. This study suggests reducing irrigation and chemical fertilizer application for stevia cultivation and increasing farmers' awareness of soil environment conservation for developing better, more sustainable agricultural management.

\section{ACKNOWLEDGEMENT}

This study was supported by the Graduate School of Global Environmental Studies, Sophia University and Graduate School of BioApplications and Systems Engineering, Tokyo University of Agriculture and Technology. This study could not have been accomplished without all the support we received. Great gratitude should be given to Professor Guangwei Hang, Hisako Umemura, Anne Mcdonald, Koki Toyota and Masachika Suzuki, who organised the field trip to Zhangye Oasis and gave advice on the study. Thanks should also be given to Xian Zhu, Jing Zhang, Tianjiao Li and Huan Liu, who made a great contribution to the fieldwork. We would also like to thank Xin $\mathrm{Li}$, Minguo $\mathrm{Ma}$ and Jian Wang from the Chinese Academy of Sciences for their generous support. We also appreciate all the farmers who responded to our interview in Linze County. 


\section{REFERENCES}

Addiscott, T. M., Whitmore, A. P., \& Powlson, D. S. (1991). Farming, Fertilizers and the Nitrate Problem. CAB International (CABI).

Ahmed, M., Salahin, M., Karim, R., Razvy, M., Hannan, M., Sultana, R., . . . Islam, R. (2007). "An Efficient Method for in Vitro Clonal Propagation of a Newly Introduced Sweetener Plant (Stevia Rebaudiana Bertoni.) in Bangladesh". American-Eurasian Journal of Scientific Research, 2(2), 121-125.

Al-Kaisi, M. M., \& Yin, X. (2003). "Effects of Nitrogen Rate, Irrigation Rate, and Plant Population on Corn Yield and Water Use Efficiency". Agronomy journal, 95(6), 14751482.

Debnath, M. (2008). "Clonal Propagation and Antimicrobial Activity of an Endemic Medicinal Plant Stevia Rebaudiana". Journal of medicinal plants research, 2(2), 045-051.

Fronza, D., \& Folegatti, M. V. (2003). "Water Consumption of the Estevia (Stevia Rebaudiana (Bert.) Bertoni) Crop Estimated through Microlysimeter". Scientia Agricola, 60(3), 595-599.

Good, A. G., \& Beatty, P. H. (2011). "Fertilizing Nature: A Tragedy of Excess in the Commons". PLoS biology, 9(8), e1001124.

Huang, G. (2015). "From Water-Constrained to Water-Driven Sustainable Development-a Case of Water Policy Impact Evaluation". Sustainability, 7(7), 8950-8964.

Jackson, A. U., Tata, A., Wu, C., Perry, R. H., Haas, G., West, L., \& Cooks, R. G. (2009). "Direct Analysis of Stevia Leaves for Diterpene Glycosides by Desorption Electrospray Ionization Mass Spectrometry". Analyst, 134(5), 867-874.

Jiang, L., \& Li, Z. (2016). "Urbanization and the Change of Fertilizer Use Intensity for Agricultural Production in Henan Province". Sustainability, 8(2), 186-197.

Jiao, Y., \& Ma, M. (2002). "Spatial Pattern in Residential Area and Influencing Factors in Oasis Landscape". Acta Ecologica Sinica, 23(10), 2092-2100.

Karizumi, N. (2010). "'How Roots Work". The New Version of the General Theory of Tree Root System with Graphics". The Seibundo Shinkousha, B(5), 734-741.

Kassahun, B. M., Kebede, W., Gebremeskel, H., \& Zigene, Z. D. (2012). "Performance of Stevia (Stevia Rebaudiana Bertoni) for Morphological and Economic Traits under Different Ecologies of Ethiopia".

Linze Government Network. (2017). "Demographic of Linze, Gansu". Retrieved from http://www.gslz.gov.cn/Item/36445.aspx

Meah, M., Harrison, N., \& Davies, A. (1994). "Nitrate and Nitrite in Foods and the Diet". Food Additives \& Contaminants, 11(4), 519-532.

Ministry of Agriculture of the People's Republic of China. (2015). "Agricultural Protection Work Progresses Smoothly in Zhangye, Gansu Province". Retrieved from http://www.moa.gov.cn/fwllm/qgxxlb/gs/201505/t20150526_4616335.htm.

Nakatsu, S. (2004). "Easy Estimation Method for Plow Pan and Effect of Improved PanBreaking". Japanese Society of Soil Science and Plant Nutrition, 75(2), 265-268.

Nian, Y., Li, X., Zhou, J., \& Hu, X. (2014). "Impact of Land Use Change on Water Resource Allocation in the Middle Reaches of the Heihe River Basin in Northwestern China". Journal of Arid Land, 6(3), 273-286.

Ojha, A., Sharma, V., \& Sharma, V. (2010). "An Efficient Protocol for in Vitro Clonal Propagation of Natural Sweetener Plant (Stevia Rebaudiana Bertoni)". African Journal of Plant Science, 4(8), 319-321.

Singh, A., \& Verma, P. P. S. (2015). "Survival and Growth Performance of Stevia Cutting under Different Growing Media". Journal of Medicinal Plants, 3(2), 111-113.

Smil, V. (2004). Enriching the Earth: Fritz Haber, Carl Bosch, and the Transformation of World Food Production. Cambridge: The MIT press.

Su, Y., Zhang, Z., \& Yang, R. (2007). "Amount of Irrigation and Nitrogen Application for Maize Grown on Sandy Farmland in the Marginal Oasis in the Middle of Heihe River Basin". Acta Agronomica Sinica, 33, 2007-2015.

The State Council Information Office of the People's Republic of China. (2015). "Gansu Zhangye: Water Saving Model for Ecological Deterioration". Retrieved from http://www.scio.gov.cn/xwfbh/xwbfbh/wqfbh/2015/20150331/xgzc32635/Document/1397 672/1397672.htm.

The Statistics Portal. (2017). "Market Value of Stevia Worldwide in 2014 and 2017 (in Million U.S. Dollars)". $\quad$ Retrieved from https://www.statista.com/statistics/329748/Stevia-s-global-market-value/. 
Wang, W., Liu, S., Kobayashi, T., \& Kitano, M. (2013). "Evaporation from Irrigation Canals in the Middle Reaches of the Heihe River in the Northwest of China-a Preliminary Study". Journal of the Faculty of Agriculture, Kyushu University, 58(2), 371-376.

Wilson, J. (1949). "Nitrate in Foods and Its Relation to Health". Agronomy journal, 41, 2022.

Wu, X., Zhou, J., Wang, H., Li, Y., \& Zhong, B. (2015). "Evaluation of Irrigation Water Use Efficiency Using Remote Sensing in the Middle Reach of the Heihe River, in the Semi-Arid Northwestern China". Hydrological processes, 29(9), 2243-2257.

Xiao, S.-C., Xiao, H.-L., Zhou, M.-X., Si, J.-H., \& Zhang, X.-Y. (2004). "Water Level Change of the West Juyan Lake in the Past 100 Years Recorded in the Tree Ring of the Shrubs in the Lake Banks". Journal of Glaciology and Geocryology, 26(5), 557-562.

Xu, H., Sui, L., Li, Y., \& Zhang, D. (2014). "The Role of Water Users Associations in Integrated Water Resource Management of Zhangye City in Heihe River Basin, China". In Squires, V. R., Milner, H. M., \& Daniell, K. A. (Eds.), River Basin Management in the Twenty-First Century (pp. 304-324): CRC Press.

Yang, R., \& Liu, W. (2010). "Nitrate Contamination of Groundwater in an Agroecosystem in Zhangye Oasis, Northwest China". Environmental Earth Sciences, 61(1), 123-129.

Yang, R., \& Wang, X. (2011). "Effects of Nitrogen Fertilizer and Irrigation Rate on Nitrate Present in the Profile of a Sandy Farmland in Northwest China". Procedia Environmental Sciences, 11, 726-732.

Yang, S.-M., Li, F.-M., Suo, D.-R., Guo, T.-W., Wang, J.-G., Song, B.-L., \& Jin, S.-L. (2006). "Effect of Long-Term Fertilization on Soil Productivity and Nitrate Accumulation in Gansu Oasis". Agricultural Sciences in China, 5(1), 57-67.

Yin, X., \& Wang, J. (2015). "Evolutional Characteristics of Heat Resources During Farming Period and Its Effect on Agricultural Production in Zhangye Prefecture". Journal of Glaciology and Geocryology, 37(5), 1406-1411.

Zhang, B. (2016). "Current Situation, Issues and Strategy in the Development of Stevia Cultivation in Yanuan Town, Linze County". Agriculture Technology and Information, 25, 10-11.

Zhang, W., Tian, Z., Zhang, N., \& Li, X. (1996). "Nitrate Pollution of Groundwater in Northern China". Agriculture, Ecosystems \& Environment, 59(3), 223-231.

Zhangye Agriculture Bureau. (2015). "Linze County Yanuan Town: Sweet Industry Is under 'Thriving'". Retrieved from http://nyj.zhangye.gov.cn/Item/53087.aspx.

Zhangye Audio and Visual Network. (2016). "Linze: Celebrating the Harvest of 35 Thousand Mu Stevia". Retrieved from http://www.zytv.cc/system/2016/09/21/010040271.shtml

Zhangye Government Network. (2016). "Stevia Has Become Farmers' 'Cash Cow'". Retrieved from http://www.zhangye.gov.cn/171/86216.html

Zhou, X., Chen, L., Zuo, Z., Chen, L., \& Li, D. (2009). "The Positive Effect of Developing Stevia Cultivation and Technology in Linze County". Agriculture Technology and Information, 23, 20-21. 